Departamento de Historia Universidad de Santiago de Chile

Revista de Historia Social

y de las Mentalidades

Volumen 25, $\mathrm{N}^{\circ} 1,2021: 219-250$

Issn Online: 0719-4749

\title{
VIOLACIÓN, JUSTICIA Y GÉNERO UN ENFOQUE MULTIDIMENSIONAL DE UNA VIOLENCIA HISTÓRICA (LA MATANZA, BUENOS AIRES, SIGLO XVIII)*
}

\author{
RAPE, JUSTICE AND GENDER A MULTIDIMENSIONAL APPROACH \\ OF AN HISTORICAL VIOLENCE \\ (LA MATANZA, BUENOS AIRES, 18th CENTURY)
}

\author{
DRA. LIA QUARLERI** \\ Consejo Nacional de Investigaciones Científicas y Técnicas \\ Universidad Nacional de San Martín \\ Ciudad Autónoma de Buenos Aires, Argentina \\ Email: liaquarleri@yahoo.com.ar \\ Id-ORCID: 0000-0002-0738-6407
}

\begin{abstract}
RESUMEN
Este trabajo se enfoca en el estudio de un proceso judicial desplegado, en Buenos Aires, tras la violación denunciada por Bernabela Franco, en el año 1778, días después de haber sido atacada por un vecino en su casa de La Matanza, estando su marido ausente. El presente análisis está precedido por una pregunta: ¿en qué dimensiones se expresó la violencia de la violación en ese contexto particular? Para ello, se reparará en las sentencias, la configuración del delito, las terminologías utilizadas y en los imaginarios de género, como también en las percepciones del daño. Consideramos que la violencia de una violación,
\end{abstract}

\begin{abstract}
This work focuses on studying the judicial process deployed in Buenos Aires after the violation denounced by Bernabela Franco, in 1778. The judicial process happened days after being attacked by a male neighbor at her home in La Matanza, being her husband absent. This analysis preceded by a question: in what dimensions was the violence of rape expressed in that particular context? These dimensions will repair in the sentences, the configuration of the crime, the terminologies used, the gender imaginary, and her perceptions of the damage. We consider that the violence of rape is multidimensional. It produced
\end{abstract} clasificaciones, transformaciones y resistencias. Río de la Plata, siglos XVIII y XIX”. Agencia Nacional de Promoción de la Investigación, el Desarrollo Tecnológico y la Innovación, Argentina (FONCyT - PICT 1409/17). 
no silenciada, era multidimensional y que producía traumas socio-emocionales, vinculados tanto al hecho como al señalamiento social y al escrutinio judicial, que devenían tras la denuncia.

Palabras clave: Violación; género; justicia colonial; Buenos Aires socio-emotional traumas linked to the fact, social signaling, and judicial scrutiny, which occurred after the complaint.

Keywords: Rape; Gender; Colonial Justice; Buenos Aires

Cómo citar: Quarleri, Lía. (2021). "Violación, justicia y género. Un enfoque multidimensional de una violencia histórica (La Matanza, Buenos Aires, siglo XVIII)". Revista Historia Social y de las Mentalidades, 25(1), 219-250. https://doi.org/10.35588/rhsm.v25i1.4676

\section{INTRODUCCIÓN}

La violación como fenómeno histórico ha sido abordada siguiendo los rastros de las formas o las maneras en que fue concebida, tratada, interpretada o ignorada. Las fuentes judiciales y los legajos criminales conforman un medio insoslayable para relevar el lugar histórico y cultural dado a las violencias, ancladas y desencadenadas, en torno a la misma. Sin embargo, la historiografía ha mostrado las complejidades que envolvían a las denuncias de violación en los Tribunales judiciales, en particular en los casos de mujeres adultas. Esto por varias cuestiones. La presentación judicial solía generar una exposición que afectaba a las mujeres que identificaban al agresor, en búsqueda de una reparación. Paradójicamente, la violación marcaba a la persona violentada, quien era señalada socialmente, en especial en ciertas épocas y espacios. A eso se sumaba la inversión de la culpa, por las representaciones de género y por la carga probatoria exigida, que además implicaba la obligación de detallar los hechos ante letrados o jueces, las veces que estos lo requiriesen. También, por el temor a una venganza del agresor o a las reacciones de su entorno familiar, al desprecio social y a las múltiples violencias que en cadena se desataban, una vez que la situación vivida era verbalizada, comunicada, denunciada y difundida. ${ }^{1}$

1 En un estudio elaborado en la década de 1980, para el virreinato de Nueva España, sobre un corpus de treinta y cuatro denuncias de violación solo dos fueron presentadas por las mismas mujeres, en el período 1790-1821 (Castañeda 706). Esto, en parte, porque la mayoría eran niñas o jóvenes y porque las mujeres debían denunciar acompañadas de su padres, madres o esposos. Esta tendencia también se registró en los expedientes del Archivo Histórico de la Provincia de Buenos Aires de los años 1760-1810 (Barreneche 36-37) y de Buenos Aires, durante la segunda mitad del siglo XIX, connotando "una baja presencia estadística" de delitos de violación de diferente 
En el mundo occidental, desde la época medieval, se condenó la violación a mujeres, a partir de leyes específicas que estipulaban extremas sentencias. ${ }^{2} \mathrm{La}$ existencia de una potencial condena no fue acompañada de la consideración de los daños ejercidos sobre las personas afectadas en su individualidad, puesto que el eje estuvo puesto, por lo menos hasta fines del siglo XIX, en los efectos morales, sociales y familiares que la violación generaba. No obstante, la tensión entre ambas dimensiones, la individual y la social, solía plasmarse en los procesos judiciales que, en sí mismos, se centraban en la mujer denunciante y en su capacidad para demostrar que el hecho denunciado había sido ejecutado por el agresor a pesar de su resistencia. Esta lógica jurídica probatoria conllevaba un escrutinio y una exposición así como la obligación de afrontar los sinuosos caminos de los poderes judiciales, cruzados por configuraciones y representaciones intimidatorias en torno a las mujeres que contaban con los requisitos jurídicos para presentar una denuncia. En ese sentido, en el contexto estudiado, la posibilidad de denunciar quedó inmersa dentro de otra escala de entramados socio-jurídicos, que excluía a mujeres adultas solteras, mujeres sin recursos económicos, mujeres indígenas o mujeres en condición de servidumbre o esclavitud. ${ }^{3}$

índole (Riva 116). Para Chile de los siglos XVIII y XIX se menciona la posibilidad de que muchas denuncias no quedaran registradas ante la mediación de un arreglo extrajudicial y se señalan los condicionantes arriba mencionados (Celis Valderrama, "Delitos"; González-Gómez; Salinas, "Violencias sexuales"). Desde la historiografía francesa, también, se dio cuenta de la complejidad y persecución que acompañaban las denuncias (Vigarello).

2 Desde la Edad Media, la violación fue concebida como un delito solo en relación con las mujeres. Se la consideró, a su vez, por mucho tiempo un ultraje a la honestidad de las mismas y una injuria familiar que afectaba el dominio de un padre, esposo, familiar o soberano. En los primeros siglos de la Edad Media, en el ámbito de Castilla, primó la represalia privada como mecanismo para dirimir o vengar la deshonra. Con el fortalecimiento del poder regio y el afianzamiento del Derecho común, los soberanos asumieron jurisdicción sobre la configuración del delito, la ejecución de las penas y la publicidad del castigo. Uno de los cuerpos legales que delimitaron el ámbito de la violación fueron Las Siete Partidas, Libro de leyes redactado en Castilla durante el reinado de Alfonso X (1221-1284). Dentro de ese corpus, la violación fue considerada un delito grave condenable con la pena de muerte, cuando aquella se ejecutaba contra mujeres casadas, viudas o vírgenes (Rodríguez Ortiz). Las Siete Partidas serán recuperadas por la administración colonial hispana y formarán parte del derecho penal colonial en América, junto con otros cuerpos normativos.

3 La estipulación del delito de violación, siguiendo Las Siete Partidas, dejaba fuera a mujeres que según la moral vigente no cumplían con los requisitos para iniciar una demanda. Asimismo, estas Leyes excluían a mujeres bajo otras situaciones socio-jurídicas, como era el caso de las mujeres indígenas que habitaban pueblos o reducciones de indios o mujeres esclavas, como ilustraremos. La sociedad colonial, por otra parte, estaba estructurada sobre derechos desiguales en relación al origen social, jurídico y al género (Fernández; Mallo, "Conflictos y Armonías" y Socolow, 
El punto de partida del análisis lo constituye la violación denunciada por Bernabela Franco, en el año 1778, días después de haber sido atacada por un vecino que irrumpió durante la noche, en su casa del Pago de la Matanza del Partido de Cañuelas, estando su marido ausente. ${ }^{4}$ Era la segunda vez que Bernabela lo acusaba de haberla violentado, ante el alcalde provincial, en su casa de ese espacio fronterizo de la campaña bonaerense. Tras ser desoída, dirigió la denuncia al virrey del Río de la Plata y a partir de entonces la causa tomó su curso en los Tribunales de la ciudad de Buenos Aires. Durante el proceso, la voz de Bernabela adquirió un protagonismo inusitado en el expediente, teniendo en cuenta que las denuncias solían y debían ser lideradas por sus maridos, como estipulaban la normativa y las costumbres. Sus presentaciones ilustran qué era posible contar en los Tribunales, sobre esquemas preconcebidos, las percepciones del daño, las expectativas judiciales y las circunstancias de vida. La posibilidad de acceder a la voz de la protagonista, con las mediaciones formales respectivas, resulta relevante si se tiene en consideración el bajo número de fuentes, en los archivos, producidas por mujeres o centradas en sus relatos (Vasallo 430-431).

Al respecto, la historiografía ha dado cuenta de ciertos cambios, observados desde fines del siglo XVIII, en donde las causas iniciadas por mujeres tomaron, por diferentes razones, una curva ascendente. En el caso del virreinato del Río de la Plata, la propia creación del mismo, en 1776, como la restitución de la Real Audiencia de Buenos Aires, en 1785, tras una breve existencia en el siglo XVII, movilizó la presentación de demandas ante los Tribunales, por parte de diferentes sectores de la población rioplatense. Por otro lado, a partir de la década de 1780, comenzó a notarse la influencia de las "corrientes propiciatorias de la libertad social de la Ilustración", en las decisiones tomadas en el terreno del derecho de

entre otros trabajos). En la concreción de una denuncia influían la cercanía a los Tribunales, la disposición de recursos económicos para afrontar los costos de desplazamientos o manutención, más allá de que fueran declaradas "insolventes", el apoyo socio-familiar y el contexto cultural receptivo o adverso, en relación a presentación de denuncias realizadas por mujeres o terceros sobre delitos ejercidos por hombres. Finalmente, el escenario socio-político, demográfico e institucional local contribuían o no en la ponderación delictiva del sujeto denunciado.

$4 \quad$ El Paraje de La Matanza se creó, en 1778, dos años después del establecimiento del virreinato del Río de la Plata, a partir del fuerte del mismo nombre fundado en 1760. Este había sido instalado al sudoeste de la ciudad de Buenos Aires, en la llamada "frontera de Las Pampas", la cual constituía un área de influencia de distintas parcialidades indígenas. Los fortines debían ser acompañados de la creación de pueblos para asentar población hispano-criolla dispersa o atraer nueva, asignándoles tierra para cultivo y ganadería (Canedo 10). En torno a esos fortines se mantuvieron relaciones hispano-indígena de intercambio de bienes, al mismo tiempo que se manifestaron "conflictos entre las distintas parcialidades indígenas que habitaban en la región y de éstas con los pobladores hispano-criollos" (Néspolo 2). 
familia (Kluger, Escenas 4). En esa coyuntura, los Tribunales laicos ganaron influencia sobre los eclesiásticos y los jueces sobre el ámbito confesional en estos temas, y las mujeres comenzaron a adquirir mayor "protagonismo y legitimidad" al ser "investidas de un sólido crédito público" en las demandas vinculadas a la "sociedad familiar", en tanto razón de estado (Cicerchia 146)..$^{5}$

La presente investigación forma parte de un proyecto mayor que indaga en las políticas de gobierno, los dispositivos de control, los castigos físicos y las violencias desplegadas sobre cuerpos marcados por las diferencias de género, origen, condición jurídica y sector social. En trabajos precedentes analizamos el rol de los castigos físicos a mujeres indígenas y criollas como condensación de esquemas disciplinares sobre el cuerpo femenino propios de la doctrina cristiana y de las culturas patriarcales, expresadas en tradiciones prehispánicas y occidentales, y como producto de un derecho penal colonial con códigos punitivos estratificados y desiguales (Quarleri, "Castigos, fugas y resistencias"). Este estudio se propone analizar los dispositivos y las violencias jurídicas, políticas, sociales y de género inscriptas en las causas de violación que remiten al cuerpo y al mismo tiempo lo trascienden. La focalización en un caso, suscitado en un paraje fronterizo de Buenos Aires, sigue una línea de investigaciones que hemos realizado sobre otras fronteras coloniales (Quarleri, "Castigos físicos"; Avellaneda y Quarleri). El expediente seleccionado se encuentra dentro de un reservorio más amplio, en proceso de indagación. ${ }^{6}$ La investigación pormenorizada del mismo se inspira en las metodologías de la microhistoria y la etnohistoria, en donde las palabras proferidas por los y las protagonistas son interpretadas en diferentes escalas y entrecruzadas con diversas temáticas.

5 El aumento demográfico en el ámbito de Buenos Aires y sus proximidades impactó en las dinámicas sociales y los vínculos interpersonales que se expresaron en diferentes aspectos. Uno de ellos fue el de las violencias hacia las mujeres, en particular de los sectores subalternos que, por su alta exposición a las agresiones y su mayor libertad frente al cumplimiento de los códigos morales socialmente impuestos, tuvieron más presencia en los Tribunales. Finalmente, en una escala mayor y en una tensa línea entre ideales de cambio, tradición y normativas vigentes, desde ciertas voces y acciones femeninas, expresadas en escritos y en prácticas concretas, se vislumbraron ciertas transformaciones impulsadas por mujeres, en ámbitos económicos, sociales y familiares (Mallo, "La mujer rioplatense").

6 Para el período virreinal (1776-1810), en los fondos catalogados como "Criminales", "Tribunal criminal" y "Juzgado del Crimen" del Archivo General de la Nación (Buenos Aires, Argentina) hasta el momento hemos registrado doce expedientes vinculados a violaciones y sustracciones de mujeres, jóvenes y niñas bajo diferentes carátulas: Raptos y tentativas de rapto a niñas (4), Violación y estupro (3), Tentativa de violación en la persona de su esposa (2), Violación y tentativa de violación (2) y Autos por haber forzado a una mujer casada (1). Cabe aclarar que en una investigación previa realizada sobre estos fondos se registraron treinta y cinco expedientes sobre violaciones de diferente índole durante el siglo XVIII rioplatense (Gutiérrez Aguilera). 
Este trabajo se enfoca en el estudio del procesojudicial desplegado en Buenos Aires, reparando en las sentencias, la configuración del delito, las terminologías utilizadas y en los imaginarios condensados, como también en las percepciones del daño. El análisis está precedido por una pregunta: ¿en qué dimensiones se expresó la violencia de la violación en ese contexto particular? Se considera que la usurpación del cuerpo de una mujer, simbolizado por el agresor como el objeto de un deseo de posesión, constituía un medio para marcar dominios y goces de poder dentro de relaciones cruzadas por violencias cotidianas, sociales, institucionales y morales. Partimos de la idea de que la violencia de una violación no silenciada era multidimensional y que producía traumas socio-emocionales, vinculados al hecho como al señalamiento social y al escrutinio judicial, que devenía tras la denuncia. En ese sentido, las pruebas y preguntas realizadas evidenciaron la existencia de una sospecha jurídica anunciada que llevaba a que las mujeres litigantes fueran prejuzgadas. Al respecto, tanto la demostración jurídica de una resistencia adecuada frente al ataque, como la desconfianza que desacreditaba a las mujeres, por ser mujeres, en particular en sus comportamientos corporales, constituyeron dispositivos socio-jurídicos que limitaron las denuncias en los Tribunales. Esto más allá del contexto histórico y cultural analizado.

Una mirada histórica de larga duración nos enfrenta con una problemática que ha atravesado el tiempo, sin cambios estructurales, pese a su antigua condena. Georges Vigarello, uno de los principales exponentes de la historia cultural del cuerpo, en su obra Historia de la violación, centrada en Francia de los siglos XVI al XX, describe las trabas sociales y judiciales manifestadas históricamente en los procesos de violación que limitaron la presentación de denuncias. Y muestra, a su vez, como la configuración del delito y la consideración del daño, en sus dimensiones emocionales y corporales, sociales e individuales, fueron variando sutilmente en los siglos analizados. En el Antiguo Régimen, la violación era consideraba un delito moral inscripto en el "amplio universo del pecado". Desde ese esquema de pensamiento, la mujer denunciante quedaba presa de una marca social imborrable. En una segunda etapa, abierta con las reformas ideológicas y políticas de fines del siglo XVIII, se evidenció una disociación jurídica entre faltas morales, religiosas y sociales, así como el desplazamiento de la escala del daño de lo social a lo individual. Finalmente, en los códigos jurídicos del siglo XIX, se vislumbró el esfuerzo por discriminar intrusiones contra las personas que atentaban contra la integridad física o contra el llamado "pudor", en sus diversas formas $(8,102$ y 180$){ }^{7}$ 
En relación al contexto colonial americano, existen pocos estudios sobre el tratamiento de la violación a mujeres adultas. Los trabajos de referencia responden a un corpus heterogéneo por las épocas, espacios, condiciones de género y perfil socio-etario de las personas estudiadas. Dentro de un universo de investigaciones disímiles, interesa marcar cuatro líneas o temáticas de investigación e ilustrarlas a través de ciertas ideas, aportes o trabajos, a los fines del presente trabajo. Una primera línea, la representan aquellos estudios que desde diferentes perspectivas y con distintos propósitos analizaron expedientes judiciales sobre abusos y maltratos hacia mujeres, en particular, en sectores subalternos de la ciudad o campaña de Buenos Aires. ${ }^{8}$ Una segunda línea está dada por trabajos que se centran en denuncias de estupro desde las perspectivas del cuerpo y las emociones, las estructuras familiares y el lugar social, cultural y jurídico dado a la niñez, en el período colonial. ${ }^{9}$ Una tercera está marcada por aquellas investigaciones que visibilizaron la problemática de la violación masculina, ocultada bajo el universo de los delitos morales y las miradas sesgadas por los propios condicionantes de género. ${ }^{10}$ Una última línea apunta a la temática de la violencia en las relaciones interpersonales coloniales, en donde la violación a mujeres conformaría un fenómeno con características específicas. ${ }^{11}$

la provincia de Buenos Aires tras la sanción del Código Penal nacional en 1886, muestra que si bien se autorizó a impulsar el juicio con la simple denuncia de la víctima, de los padres o de un tutor, las complejidades en torno a la carga probatoria como el peso de las valoraciones y prejuicios de género siguieron impactando en los procesos judiciales y en las sentencias $(102,104,116)$.

El interés por este tipo de fuentes históricas se manifestó en la historiografía especializada en la región de Buenos Aires, desde la década de 1980, poniendo el foco en la violencia colonial de las relaciones de género, expresadas en la legislación y en el tratamiento judicial diferencial para hombres y mujeres y en el universo de los vínculos sociales y familiares (Barreneche; Cicerchia; Gutiérrez Aguilera; Kluger, "El rol femenino"; Mallo, "La mujer"; Sidy; y Socolow, entre otros). El estupro era definido como un acto venéreo con una mujer virgen. Tras la denuncia de un acto llevado a cabo sin consentimiento comenzaba un complejo proceso para demostrar la violación. Se estipulaba la figuraba del rapto si jóvenes, niñas o doncellas habían sido desplazadas, espacialmente, utilizando la fuerza, el engaño o la manipulación. Desde el punto de vista jurídico, el delito imputaba las consecuencias sociales y morales de la llamada "desfloración" fuera del matrimonio. Por la carga probatoria, las marcas corporales y el desagravio a la tutela paterna, estos casos eran denunciados con mayor frecuencia, al mismo tiempo que detrás de los mismos se erigía una multiplicidad de escenarios de dolor y trauma, violencia intra-familiar, pobreza y abandono de niños y niñas (Celis Valderrama, "Ahora veremos"; Plaza; Sidy, "El cuerpo de Lorenza", entre otras investigaciones).

10 A través de la figura de la sodomía, entendida desde la teología moral como pecado nefando o pecado de lujuria, se penaba con castigos extremos a las relaciones sexo-amorosas entre hombres (Molina 28). Dentro de este marco ideológico-jurídico, el delito de violación como tal no fue contemplado. Esa situación cambiaría solo parcialmente en la Argentina, a partir de la reforma al Código Penal de 1903, que incluirá como víctimas del delito de violación a varones por debajo de los 12 años (Riva 120).

11 El ejercicio de la violencia era comúnmente utilizada en la intermediación de conflictos, honores ofendidos, disputas por derechos de propiedad, venganzas por robos e injurias verbales, 
Desde un punto de vista conceptual partimos de enfoques teóricos que interpretan a la violencia que encarna la violación a mujeres en vinculación con un enraizado conjunto de estereotipos históricos, narrativas culturales y mandatos de género, sobre sus cuerpos y emociones. Al respecto, Sharon Marcus, en su clásico trabajo de la década de 1990, esclareció el complejo entramado emocional, social y jurídico dentro del cual las violaciones son ejecutadas, leídas y judicializadas, apelando a una lógica gramatical basada en guiones culturales estructurados sobre violencias misóginas. Para la autora, en el contexto observado, la violación perpetuada por hombres a mujeres no consistía solo en un ataque con fines sexuales sino una agresión corporal y emocional que expresaba una invasión al espacio interior, con el objeto de imponer la diferencia de género mediante la violencia (81-82). En esa línea, Rita Segato, ha remarcado en diferentes trabajos que la violación a mujeres debe interpretarse dentro una economía simbólica del poder, cuya marca es el género, que se actualiza en virtud de la sobrevivencia histórica de un núcleo duro de sentido de prolongada vigencia (12-13). A partir de un caso paradigmático, inserto dentro de una violencia histórica que ha atravesado y atraviesa diversos sistemas sociales y culturales, se busca sumar al trazado de una genealogía de comportamientos enquistados. En este caso, indagando en el tratamiento judicial originado tras la denuncia de una mujer campesina que se hizo escuchar, a fines del siglo XVIII, desde un espacio rural y fronterizo, próximo a la ciudad de Buenos Aires.

\section{EL DERROTERO JUDICIAL Y EXTRAJUDICIAL DE UN CASO DE VIOLACIÓN}

La denuncia que dio curso al proceso judicial fue realizada a través de un escrito dirigido el virrey del Río de la Plata Pedro de Ceballos, a principios de 1778, por Bernabela Antonia Franco. Una joven mujer campesina, madre de varios niños y niñas, que solía quedarse sola en su rancho de campaña, cuando su marido se ausentaba para trabajar temporalmente en el cultivo o la cosecha. En su presentación, Bernabela describió crudamente la situación padecida, al mismo tiempo que relató que se trataba de un segundo ataque perpetrado por el mismo agresor. Previamente, había realizado una denuncia ante el alcalde provincial de la Santa Hermandad de La Matanza, Diego Mantilla. Pero este no dio respuestas

señalamientos de autoridad, coacción económica y reforzamiento del valor de la masculinidad, entre otras cuestiones (Celis Valderrama, "Delitos" ; González-Gómez; Salinas, "Violencias sexuales" y Salinas, "Violencias interpersonales"). 
concretas. Lo que constituyó un primer eje de la violencia que fue alimentando el daño y el trauma. En contraste, el virrey dio curso inmediato al proceso, en un claro gesto de distanciamiento con la inacción precedente. ${ }^{12} \mathrm{El}$ juicio se extendió a lo largo de un año y concluyó tras la sentencia del nuevo virrey de Río de la Plata, Juan José de Vértiz y Salcedo. En el ínterin, el acusado fue encarcelado, el juez de la causa y el fiscal buscaron imponer su veredicto, y Bernabela reclamó justicia mientras el defensor del agresor desplegó sin escrúpulos su oficio, en base a una gama amplia de artilugios socio-jurídicos.

En su escrito Bernabela Antonia Franco declaró que:

El 25 de este mes estando en mi rancho sola con mis criaturas a la medianoche se apareció en mi rancho, Felipe Sánchez, vecino de dicho paso, determinadamente a forzar mi honestad con el cuchillo en la mano que me puso en la garganta y practicó cuanto quiso su malicia conmigo y después del hecho tan infame procuró despojarme de algunos cortos números de plata que había en casa demostrándome querer quitarme la vida y hallándome en aquella desdicha tan desamparada dejé todo a su discreción pues me veía sola motivo de haber ido mi marido a regar a las chacras de afuera por cuyo motivo me era tan forzoso experimentar todo el desastre referido. Siendo esto señor excelentísimo ya de segunda vez que dicho Sánchez ha mancillado mi honor del mismo modo que esta última vez referida y en la primera ocasión di parte al señor alcalde provincial que expidió orden para el capitán Antonio Magallanes que se le dio tan poco que no puso en ejecución el prenderlo y estando yo con este descuido ha vuelto a ejecutar de segunda vez todo lo referido. (AGNA, Tribunales, Juzgado del Crimen, legajo 28, expediente 16, no. 2778, f. 497 ${ }^{13}$ ).

Felipe Sánchez era un vecino de 60 años de edad, originario del Paraguay. Conocía a Bernabela y a su marido desde que pasó a residir en el mismo paraje. Además de trabajar en su campo, Sánchez solía ser reclutado en ciertas instancias en el puesto de la Guardia de frontera de La Matanza. Por su vecindad y por su conocimiento sobre los movimientos en el rancho de Bernabela, se puede inferir

12 La administración de justicia en el ámbito rural, junto con las funciones de policía, fueron delegadas en los alcaldes provinciales, cargo al que se accedía por compra, y en los alcaldes de la Santa Hermandad, lo cuales eran elegidos por el cabildo de Buenos Aires (Barral y Fradkin 22; Barriera 361).

13 En adelante, Juzgado del Crimen. 
que los ataques fueron premeditados. En su escrito, Bernabela solicitó se hiciese efectiva la detención y se lo castigara con "durísimas penas". Además, reclamó el resarcimiento económico por los daños ocasionados, tal como contemplaba la legislación. La presentación realizada al virrey tuvo efectos concretos, pese a que la justicia no permitía que las mujeres, consideradas jurídicamente bajo tutelaje de maridos, padres o madres viudas, se presentaran ante la misma sin respaldo familiar. Esto pudo deberse, como veremos, a una sumatoria de factores, entre ellos a una cultura jurídica caracterizada por una informalidad judicial y a ciertos cambios emergentes en relación a la participación de las mujeres en los Tribunales.

Pocos días después de la denuncia, el virrey ordenó el arresto, el embargo de los bienes del acusado y la investigación del hecho, a través de una sumaria judicial. La localización de Sánchez no fue inmediata. Esta cuestión, que era recurrente en la campaña de Buenos Aires dada la distancia a recorrer y los pocos recursos existentes para remunerar a comisionados o auxiliares, tomó un giro particular. Tras una averiguación de su paradero se dio a conocer, a través de un vecino, que el general Lalinde "lo había llevado a la guardia porque dicho mayor había tenido la noticia que lo querían prender a pedimento de Bernabela Franco y para libertarlo y hacerle bien y buena obra lo había puesto en dicha guardia" (Juzgado del Crimen, f. 504). Confirmada la situación, Lalinde arguyó que estaba "empleado" en la Guardia por el "castigo que se le había dado en pena de su delito", aludiendo a un arreglo extrajudicial. Al solicitar la entrega de Sánchez, el sargento se resistió apelando a su jurisdicción militar. Al respecto, sin saber el origen de la orden, adujo que solo el virrey "podía bajar a un soldado que estaba empleado en actual servicio" y que en "guardia mide otra justicia ordinaria" (Juzgado del Crimen, fs. 501, 504 y 504v). La argucia de apelar al fuero militar no era excepcional, en el contexto colonial, y en particular en los espacios de campaña fronterizos. También era usual que los acusados se refugiaran en conventos o esferas donde regían otros fueros.

El servicio en la Guardia de frontera como forma de castigo, acordado entre el alcalde de la Santa Hermandad, Juan Manuel de Echevari y el sargento Lalinde, en presencia del marido de Bernabela, José Clemente Medina, fue invocada posteriormente por Sánchez al describir cómo de forma obediente respondió al ser llamado por las autoridades del paraje a los fines de dirimir la situación, luego de participar de una misa (Juzgado del Crimen, fs. 506 y 506v). La existencia de un acuerdo, aunque constituyera una práctica consuetudinaria, tenía un valor político como parte del despliegue de un arreglo entre pares de género. La estrategia y las argumentaciones de Lalinde, arriba mencionadas, podrían interpretarse en medio de una red de apoyo activada por un conclave de varones, con poder local, a fines de impedir la exposición de una denuncia 
que simbolizaba, en términos de Rita Segato, una afrenta a una comunidad de pares o un jaque a la autoridad masculina (36). Finalmente, por orden del virrey, Lalinde debió ceder y entregar a Sánchez, el cual fue conducido a la Real cárcel de Buenos Aires. En su confesión, tomada por el alcalde provincial Diego de Mantilla, afirmó, entre otras cosas, haber "violentado" a Bernabela luego de ingresar a su casa, por la noche, sabiendo que su marido no se encontraba en ella (Juzgado del Crimen, fs. 506 y 506v).

De la confesión de Sánchez resultó una sentencia por parte del alcalde de primer voto de Buenos Aires, sin mediar testimonios u otras pruebas. ${ }^{14} \mathrm{La}$ existencia de una resolución sin una sumaria daba cuenta de una "informalidad" procedimental, generada en el ámbito de la justicia rural y sostenida por la justicia capitular porteña. Al respecto, la historiografía especializada ha descripto las características de la justicia rural, en diferentes períodos, haciendo hincapié en las competencias o conflictos con la justicia capitular de la cual dependía. La misma estaba conformada por vecinos o "notables" locales que se ocupaban de otras funciones, como era el mantenimiento de sus campos sin contar con recursos adicionales. En consecuencia, la falta de continuidad en muchas de sus acciones fue relativamente usual (Fradkin 89-90). En particular, los alcaldes de la Santa Hermandad solían aludir a las dificultades en el ejercicio de sus funciones, en el ámbito rural rioplatense, por la extensión espacial que debían recorrer sin la asistencia de otras personas (Barriera 357-358). No obstante, sus causas debían ser revisadas por los alcaldes de primer y segundo voto de la justicia capitular (Fernández 276). Por lo tanto los juicios pasaban por múltiples intervenciones, las cuales eran ejercidas por un heterogéneo cuerpo de magistrados. ${ }^{15}$ En el caso analizado, la falta de testimonios, es decir, del relevamiento de personas del partido que "supiesen del hecho", fue interrumpida por el alcalde de la santa hermandad, comisionado y cuadrillero, Thimotheo Alvarez Campana, priorizando la cosecha de trigo (Juzgado del Crimen, f. 503). Esto conllevó a que no hubiera "pruebas testimoniales" de un acto que, justamente, era llevado a cabo sin testigos.

Asimismo, puede pensarse que las reiteradas acciones de Sánchez derivaron en que se intentara un arreglo extrajudicial para evitar su publicidad, tal como se ha

14 Las pruebas judiciales de un una violación estaban conformadas por las marcas corporales, cuando correspondía, o signos físicos del ataque, el testimonio de dos testigos, aunque fuera cometido "en yermo o despoblado", la confesión del reo y la denuncia acompañada por la presentación del marido. Los testimonios, cuando se hacían, solían redundar en preguntas en torno a la "fama" y "reputación de quien había realizado la denuncia.

15 Cabe aclarar, el carácter letrado de fiscales, procuradores, alcaldes provinciales y virreyes, en contraposición con el carácter lego de los alcaldes de la Santa Hermandad. 
observado en otros casos. Celis Valderrama, para Chile colonial, hizo hincapié en que las denuncias de violación instalaban en el espacio público el escándalo, dando lugar a las especulaciones en torno al suceso, por lo que muchas causas tomaban curso legal cuando el bullicio social lo exigía (Celis Valderrama, Delitos 4-5). En lo que hace a la justicia colonial, la existencia de una cotidiana flexibilización del orden procesal determinaba "la relajación en el rigor de los medios probatorios" y predisponía a los jueces a "sacrificar las solemnidades del proceso" (Agüero 48). Dentro de una cultura jurídica donde lo esperable distaba de lo actuado el fiscal, el alcalde de primer voto como el virrey dieron su parecer y dictaron sentencia, sobre la base de la denuncia, la confesión y las actuaciones de la defensa.

La denuncia tomó el carácter de delito o crimen, siguiendo una antigua ley medieval que condenada la violación a mujeres casadas. ${ }^{16}$ Dentro de este marco socio-jurídico se caratuló al expediente y, también, se pronunció el fiscal nombrado para la causa, José Luis Cabral. Este último, citando la Ley 3, Título 20, Partida 7 de Alfonso X, que dictaminaba que "robando alguna ome alguna mujer viuda de buena fama o virgen o casada o religiosa o yaciendo con alguna de ellas por fuerza si le fuese probado en juicio debe morir" y sus bienes dados a la mujer afectada, manifestó que Sánchez debía ser castigado con la pena del último suplicio por el "atrosísimo crimen de haber violado la honestidad de una mujer casada con el auxilio de las armas". De forma inmediata, el alcalde de primer voto Judás José de Salazar, diferenciándose de la pena extrema promovida por el fiscal, condenó a Felipe Sánchez en tanto "reo confeso y convicto de la violencia de que fue acusado" a destierro en uno de los presidios del virreinato por el tiempo de diez años, a ración y sin sueldo. La defensa de Sánchez, por su parte, cuestionó los castigos imputados. Por un lado, recordó que la pena de muerte no estaba "en uso" por lo cual debía conmutarse por presidio o galera. Por otro lado, consideró que la pena en un presidio, por el lapso de diez años, "equivalía a una pena de muerte" (Juzgado del Crimen, fs., 509, 511, 511v, 513 y 514).

Sin embargo, Bernabela tomó conocimiento, a través del escribano, que Sánchez había logrado conmutar el castigo de destierro por el trabajo en la obra y construcción de la Iglesia de San Juan de las madres capuchinas. Lo que incrementó, como veremos, su sensación de injusticia y dolor. Finalmente, el 28

16 La justicia en Hispanoamérica se basó para expedir sentencias en un heterogéneo cuerpo de leyes contenidas en el derecho castellano e indiano. En el caso de la legislación indiana, la casuística fue generando un conjunto de precedentes judiciales que marcó jurisprudencia. A eso se sumaban los tipos y grados de castigo, según el estatus social del acusado o acusada, y las respuestas judiciales en función del origen de los y las denunciantes. 
de enero de 1779, el virrey Juan José de Vértiz, "atendiendo a la dilatada prisión" determinó una condena de seis años en uno de los presidios del virreinato. En el escrito remarcó que el proceso se había realizado con "notoria informalidad" ya que, si bien Sánchez había declarado "parte de los delitos", la confesión no se había incluido dentro de la Sumaria. Además, se había sustanciado la causa sin la presencia del Fiscal Real. Por último, el virrey aludió a otro aspecto que sumaba informalidad al proceso pero daba indicios de un posible cambio. Se había admitido "a una mujer a juicio sin consentimiento del marido" aunque hubiese "virtualmente presentado el requerimiento de la causa" (Juzgado del Crimen, f. 523 y 536v).

Las penas corporales constituían uno de los principales castigos dentro del sistema penal colonial. ${ }^{17}$ Hacia fines del siglo XVIII, desde la metrópoli se expresaron voces que proclamaron menor dureza en las penas corporales y cuestionaron la pena de muerte. Al respecto, bajo el "utilitarismo borbónico", inspirado en ciertos paradigmas de la modernidad iluminista, se proyectaron cambios en la administración, el gobierno, en la valoración productiva de la población colonial y en la estipulación de las penas. Todo lo cual pudo influir en las características que adquirió el proceso analizado, además de la superposición de jurisdicciones y legislaciones. En esa línea, los castigos estipulados oscilaron entre la incorporación a una guardia de frontera, realizada por el sargento Lalinde; la pena de muerte, fomentada por el fiscal; la condena a diez años en algún presidio lejano, como dispuso el alcalde de primer voto; el servicio personal en las obras de una Iglesia de la ciudad, mediada por la justicia de Buenos Aires, y, finalmente, la reclusión en un presidio del virreinato por seis años, sentenciada por el virrey. Las diferentes penas dieron cuenta, por un lado, que pervivían resquicios de una posible sentencia judicial extrema como "castigo ejemplar" a la violación de una mujer casada y, por otro lado, la falta de uniformidad punitiva. ${ }^{18}$ Asimismo, mostraban que la intención de arrogarse el tributo del castigo físico del reo traducía una disputa, entre los diferentes agentes, funcionarios y jurisdicciones coloniales, por los beneficios materiales de un

17 Los castigos corporales más comunes eran los presidios, los trabajos, las cárceles y los azotes. La cárcel era concebida, en la legislación penal, como una reclusión cautelar hasta la condena. Sin embargo, en la práctica se concibió en sí misma como una pena corporal. En el caso de los sectores sin recursos materiales, la cárcel, los trabajos y los azotes constituyeron la principal forma de castigo en contraposición con las penas pecuarias (Tomás y Valiente).

18 Este tratamiento punitivo de las violaciones a mujeres fue descripto también por la historiografía francesa y se vio reflejado en los escritos jurídicos como en el comportamiento de los jueces, dejando margen a la costumbre y a la jurisprudencia local (Vigarello 23-24). 
delito a los fines gubernamentales. ${ }^{19}$ Por último, como veremos, la ambigüedad fue un terreno propicio para la manipulación de los alcances del delito, sobre un sustrato ideológico, escrupulosamente hilvanado.

\section{EL ENTRAMADO DE LA VIOLENCIA}

La lectura del expediente estuvo guiada por la identificación de categorías, términos y expresiones que permitiesen dar cuenta de las esferas analíticas referenciadas para impugnar la violación denunciada. El interés se centró en identificar en qué circunstancias se estipulaba el delito de violación a mujeres y qué rol cumplían las estructuras de poder, la cultura jurídica y el universo de las mentalidades y moralidades en la perpetuación de un acto de violencia de género escasamente denunciado. La existencia de dispositivos socio-jurídicos, tales como la sospecha sobre la legitimidad de la violencia denunciada, en torno a un avasallamiento corporal no consentido, quedaron cristalizadas en la figura de la resistencia adecuada, también en la naturalización del uso de la fuerza para concretar una justificada compulsión masculina, desplazada de la esfera de delito. Esto, que se expresó directamente en la confesión del agresor y en las argumentaciones de la defensa, quedó reflejado en la indefinición de la violencia de la violación por parte de la legislación y los magistrados. Bernabela, en representación de otras mujeres, buscó mostrar cómo quedó presa de estas ambigüedades y violencias jurídicas, señalando un elemento más en relación con la configuración del daño.

Cabe señalar que la literatura histórica que abordó el tema incluyó el término sexual para referirse a la violación, entre otros delitos. ${ }^{20}$ En el contexto de la época, la palabra "sexo" era usada, para distinguir a hombres y mujeres siguiendo las marcas corporales de su biología y genitalidad. La sexualidad, entendida como una práctica vinculada a un placer, estaba en términos generales moralmente condenada para las mujeres, por lo menos desde los escritos teológicos y jurídicos que marcaban la norma social. Por el contrario, estaba vinculada a un débito conyugal y a la reproducción, dentro de esa esfera, para cuidar el linaje, la estirpe, la sangre, el patrimonio y la reputación. La expresión

19 El embargo de los bienes, para saldar los sueldos de los comisionados y no para reparar a las personas damnificadas, como se estipulaba por ejemplo en el caso de una violación, expresó también una apropiación gubernamental de los mismos.

20 En la literatura específica se utilizan las categorías de "violencia sexual", "delito sexual", "conductas sexuales irregulares", "experiencia sexual", "ataque sexual" para referirse a delitos catalogados en los expedientes como estupros, forzamientos, raptos, violaciones e incestos. 
sexual, dentro del contexto estudiado, debe contemplar sus diferentes aristas. Desde el universo jurídico de ese entonces, la violación era juzgada como parte de un conjunto heterogéneo de delitos morales. ${ }^{21}$ El término sexual no está consignado en los documentos. En suma, el uso del mismo para referirse a ciertos delitos, tal como se ve reflejado en algunas investigaciones, resulta discutible. Finalmente, consideramos que la violación, si bien se materializa en el cuerpo, constituye y constituía un acto total de apropiación de una persona, entendida como una integridad, a partir de la subyugación de la misma por imposición física, emocional, por amenaza y engaño, en sus más diversas formas.

En la coyuntura histórica estudiada, la estipulación del delito de violación dependía de varios factores. Entre ellos, la condición social y jurídica de las personas y la valoración moral de las mismas, ponderada jurídicamente a través de testigos. La Ley de las Partidas, arriba citada, circunscribía el delito de violación a las mujeres vírgenes, casadas, viudas de buena fama o religiosas. Ello dejaba fuera a mujeres adultas solteras, no vírgenes, mujeres que hubiesen iniciado un divorcio o que siendo viudas daban "indicios" de comportamientos condenables por la moral vigente. La "evaluación" de su "calidad moral", realizada por sus propios vecinos o conocidos, estaba en íntima relación con la valoración de su denuncia y su palabra, ya que las mujeres eran potencialmente culpables de cualquier acción asociada a sus cuerpos. Desde esa óptica, una violación podía no ser interpretada como tal, motivo por el cual ni siquiera era denunciada o si era denunciada no era tomada en cuenta. Esto se constituía en norma en el caso de mujeres indígenas o mujeres bajo condición de esclavitud.

A título ilustrativo, se puede mencionar que en las misiones jesuitas del Paraguay, la violación a mujeres adultas no fue concebida como tal por lo cual no fue penada ni judicializada. Incluso fue interpretada por autoridades de la Orden como consecuencia de un desliz moral vinculado a la naturaleza masculina. Ejemplo de aquello lo constituye la orden de un provincial, elaborada para limitar los castigos físicos dados por alcaldes o corregidores indígenas a hombres y mujeres de las reducciones guaraníes. En esa ocasión, el provincial Ignacio de Frías ordenó que se solicitara autorización a los religiosos para impartir castigos corporales, como medio punitivo a la población reduccional, para evitar que los mismos se utilizaran para "vengarse de los que tienen por contrarios, o por conseguir por medio y fuerza de las mujeres el cumplimiento de su torpe afición" (BNM. Libro de Órdenes, ms.

21 El derecho castellano definió a la violación como un delito vinculado a la moral, la honestidad y las buenas costumbres, junto con la "amistad ilícita", el concubinato, el adulterio, la sodomía y el incesto. En ese sentido, caratuló a todos como delitos morales sin diferenciar, internamente, a los que incluían violencia, fuerza, maltrato o abuso. 
6979, f. 197). En el caso de mujeres esclavas, la coacción forzada de las mismas por sus "amos" conformaba una violencia estructural. Esto quedó soslayado en el contexto de una denuncia por sevicia, realizada en Buenos Aires, en 1785. A los fines de probar los maltratos y obtener papel de venta, María del Pilar se presentó ante la justicia capitular, denunciando entre otras cosas que su "amo" Jazinto Tarazona la castigaba "sin tener ni aún un trato frenado para la cama" (AGNA. Sala XI. Criminales, legajo 28, expediente 16, número 2778, f. 90).

Lajudicialización de la crueldad reflejaba el perfil paternalista de la legislación indiana sobre quiénes habían sido previamente despojados de su condición de personas o sujetos jurídicos (Moriconi 3). Sin embargo, el marco legal que daba amparo restringía, al mismo tiempo, las posibilidades de romper con las estructuras estamentales y patriarcales. La justicia colonial, en ese sentido, funcionaba como resorte para canalizar y frenar cualquier indicio de quebrantamiento del orden social, en una fina frontera entre protección y castigo. En esa línea, la justicia colonial no condenó la violencia masculina sobre las mujeres cuando esta se ejercía fuera de ciertas estructuras sociales, familiares y jurídicas.

En las ocasiones en que se concebía el delito de violación, la obtención de una sentencia favorable era esperable si la denunciante y el contenido de lo denunciado respondían a los parámetros jurídicos esperados. Pero la interpretación del contenido de las leyes o la elección del corpus jurídico dependían de otro conjunto de variables, tales como la formación, asesoramiento o rol de los magistrados, los vínculos de poder pre-existentes o la interpretación de la gravedad del hecho. El juicio analizado se caratuló como "autos contra Felipe Sánchez por haber forzado a una mujer casada". El verbo forzar dejaba explícito el uso de una fuerza física, la amenaza o la coacción para obtener algo, contra la voluntad de la persona afectada. La expresión mujer casada precisaba el orden socio-conyugal, en que el delito se inscribía. Sin embargo, en una lógica dispar, en el expediente se aludió al hecho en dos sentidos. Por un lado, los alcaldes provinciales lo describieron como "atrevimiento semejante" o como "atrevimiento con "demasía", siguiendo términos legales antiguos. Por su parte, el alcalde de primer voto Judás José de Salazar y el fiscal José Luis Cabral se refirieron, respectivamente, a "la violencia de la que fue acusado" Sánchez y al "atrosísimo crimen" ejecutado al haber "violado la honestidad de una mujer casada" (Juzgado del Crimen, fs. 409, 502, 509 y 513).

La violencia, sin embargo, era referenciada inespecíficamente como medio coactivo, mientras que la tipología de delito grave estaba vinculada a la condición de mujer casada y al perjuicio que el acto generaba en la estimación de su persona. El honor femenino se constituía en un valor social estructural que actuaba como principal capital simbólico, en la trama de relaciones sociales y accesos a derechos de la cultura hispano-criolla. Pero violentar a una mujer casada instituía, además, 
un avasallamiento sobre la jurisdicción o dominio de su marido. A su vez, violar la honestidad de una mujer implicaba poner en duda su credibilidad, tachar su imagen y condenarla a la difamación y a la degradación pública. En virtud de que las mujeres, desde los imaginarios regidos por principios inherentes a la teología moral, eran adjetivadas por su potencial impureza, pecaminosidad y culpabilidad (Araya; Delumeau; Quarleri, "Castigos, fugas y resistencias"). Lo cual configuró un entramado ideológico y simbólico, profundamente arraigado en la cultura occidental, que justificaba la sujeción o subordinación a un sistema patriarcal y tenía consecuencias en el terreno judicial. De ahí que en una denuncia de violación se debiera demostrar la inocencia, más que probar la violencia sobre ellas ejercida.

Para dimensionar esto último, resulta necesario detenernos en la confesión del acusado, Felipe Sánchez, y en las argumentaciones de la defensa. A pocos días de su detención, Felipe Sánchez confesó haber "violentado" a Bernabela, tras entrar a su casa a altas horas de la noche, sabiendo que su marido no estaba presente. Y detalló que

Agarrándola del pescuezo le dijo que se dejase estar que el confesante iba a dormir con ella porque de lo contrario que si hablaba la había de matar y en efecto así lo hizo y el confesante la gozó con cuyo motivo se retiró a su casa sin que lo sintiese según le parece una mujer que estaba durmiendo a los pies de la cama de la citada Bernabela (Juzgado del Crimen, f. 506).

Sánchez labró un acto total de posesión de Bernabela hasta el límite de amenazarla con quitarle la vida, obligándola a "dejarse estar", silenciada y despersonalizada. Sin embargo, lo hizo en tanto era una mujer que conocía y que formaba parte de la esfera de dominio de otro hombre. En la convergencia de todo ello, el goce perverso representaba un goce de poder, detallado, nombrado y confesado. También una naturalización de la puesta en práctica de un tipo de sexualidad masculina sobre la base de la sumisión y despersonalización femenina. Al respecto, Alain Corbin, al abordar la problemática desde la perspectiva de los estudios del cuerpo, afirma que la historia de la violación es en gran medida tributaria de la historia de las representaciones literarias, en torno a las prácticas sexuales, que han mostrado a la mujer como un botín o como presa pasiva de una energía masculina posesiva (230). ${ }^{22}$ Un acto de dominio como el descripto

22 Relatos culturales que pueden rastrearse en la mitología griega, la biblia y la iconografía medieval, entre otros registros discursivos y artísticos (Koulianou-Manolopoulou y Fernández Villanueva). 
por Sánchez, ejercido en el espacio íntimo, era posible de ser verbalizado y socializado, incluso en un espacio jurídico, por la impunidad, trivialidad e insignificancia con la que era concebido.

La riqueza del análisis judicial radica en que a través de las intervenciones proferidas es posible acceder a las intenciones, los hábitos, los presupuestos y los imaginarios que se ponen en juego para cuestionar, tensionar, recrear o legitimar los sistemas sociales vigentes. Dentro de este, los defensores representan figuras paradigmáticas, en virtud de que los mismos solían desplegar una multiplicidad de recursos y discursos con el fin de cumplir con el objetivo de la defensa, ya sean solventados o en su rol de defensores de menores, pobres o naturales. El defensor general de pobres Cecilio Sánchez de Velasco nombrado para representar a Felipe Sánchez, tras declararse insolvente, no fue la excepción. Desplegó su patrocinio contra el acusado en seis presentaciones que fueron entretejiendo una ideología de género que fue revelando, a su vez, los dispositivos a través de los cuales el sistema judicial patriarcal legitimaba y perpetuaba la violencia contra las mujeres. En una primera instancia, el defensor se refirió a la "queja de Bernabela Franco de haberla gozado con violencia", siendo el único magistrado que definió a la violación como un acto que incluía la imposición forzosa de un goce personal, pero sin atribuírselo a Sánchez. Por el contrario, buscó demostrar que había existido un consentimiento o una endeble resistencia. Por su parte, también fue el único que utilizó en el expediente el verbo violar al aludir a los autos "formados contra su parte acusado" de haber "violado" y "forzado" a una mujer, en relación con el pedido de apelación al virrey (Juzgado del Crimen, fs. 511 y 515). En esa instancia, usó los términos violar y forzar a una mujer, sin incluir el estatus de casada, que era la figura que dimensionaba jurídicamente el delito, en este caso.

Frente a las apelaciones de Bernabela, Velasco cambió radicalmente el eje de su defensa. Abandonó los términos arriba mencionados y pasó a definir el hecho confesado, por su defendido, como un "exceso que no merecía semejante castigo", conllevando el suceso a dimensiones sociales y morales y extendiendo la carga de culpa a la primera. En esa línea, definió el suceso descripto por Sánchez como "pecado de incontinencia", en tanto delito moral imputado frente al impulso o desenfreno masculino (Juzgado del Crimen, f. 511 y 517). De esa forma, pergeñó que su defendido había cometido adulterio, asociándolo a una imputación de antigua tradición, por lo que ya había sido castigado tras haber sido "empleado" en la Guardia de la frontera del paraje de La Matanza. La expresión utilizada remitía a varios escenarios. En primer lugar, a las esferas de la moralidad y la justicia, en tanto el derecho y la teología constituían "dos facetas del mismo saber que se juntaban y se entremezclaban" (Herzog 906). En segundo lugar, al "universo del pecado" dentro del cual se condenaba moralmente a ambos implicados, ya que 
la persona afectada quedaba "atrapada en la imagen del acto" por su exposición a un suceso "abominable" (Vigarello 8 y 63). Finalmente, a la relación entre violación, pecado y deshonra, en la que los confesionarios del siglo XVIII, tal como lo mostró Carmen Casteñada para el virreinato de la Nueva España, tuvieron especial influencia (703-704). Estos anclajes conceptuales pervivían junto a nuevas percepciones sobre los daños sociales de una violación. En ese sentido, la violación como delito contra las personas se iría despegando lentamente del ámbito del pecado, desde fines del siglo XVIII.

La apelación a un antiguo entramado ideológico, moral y social se plasmó en el desplazamiento discursivo realizado por el propio defensor, al utilizar primero los términos violar, forzar o violentar y luego omitirlos para remitirse a la categoría de pecado. Esto marcó el tono de su defensa en la última fase del juicio, junto con el amedrentamiento simbólico hacia Bernabela, en particular poniendo en juego los efectos sociales de su denuncia. Al respecto, ante el reclamo de una reparación material, Velasco instó a que "en méritos de justicia se ha de servir despreciar y cortar la pretensión de dicha Bernabela por extravagante", la cual "puede redundar contra su propia estimación". La exposición social que enfrentaban las mujeres tras la denuncia actuaba como un mecanismo instituido para frenar las presentaciones judiciales. Ese temor se anidaba en las dudas que se buscaba sembrar, sobre ellas, manipulando la frontera entre un acto forzado y otro consentido. Desde esa lógica, en su última presentación, Velasco expuso su defensa sobre la base de un entramado teórico de subyugación de la voluntad femenina que legitimaba la apropiación masculina de sus cuerpos:

La fuerza que le hizo Felipe Sánchez consta que es aquella que llama compulsión que consiste en obligar a uno con amenazas que le ingieran justo miedo a hacer una cosa, el miedo de la Bernabela no fue justo pues en un varón constante no caería el cometer un pecado moral por temor de una amenaza que ni aun con fundamento tenía que creerla verificable no conociendo el carácter del agresor ella se preocupó de tal suerte que su resistencia no fue bastante a despertar otra mujer que dormía a los pies de la cama como es constante en los autos no así como en el muestro en que voluntariamente se entrega a él al solo impulso de una amenaza [...] no me persuado a que la dicha Bernabela estuvo en plena libertad, yo la creo atemorizada y perturbados sus sentidos, ella no supo lo que hizo ni tuvo tiempo de reflexionarlo, pero nada de esto en lo externo le sirve de favor, por tanto pido y suplico se sirva proveer como llevo expuesto (Juzgado del Crimen, f. 536 y 536v). 
El defensor de Sánchez incluyó la figura de la compulsión y la definió como una coacción que se ejercía a través de la amenaza y el miedo. Lo que pretendía era argumentar que sabiendo que esa amenaza existía y conociendo "el carácter del agresor", Bernabela debió haber ejercido una fuerza suficiente para resistir el ataque. Al respecto, Georges Vigarello, en su obra Historia de la violación describe cómo la forma de resistir o de describir la resistencia conformaba un signo de importancia para juzgar si la mujer en cuestión había sido violentada. La "víctima", dice Vigarello, debía mostrar que "había resistido físicamente desde el principio". Se esperaba una resistencia "sin falla" sobre el presupuesto de que todas las personas disponían de medios suficientes para defenderse. Su capacidad de respuesta entraba dentro de una valoración moral, una escala de juzgamiento de la mujer denunciante, incluso bajo el efecto de alguna bebida o brebaje (64-66) ${ }^{23}$

A partir de la figura de la resistencia, el defensor soslayó que la Ley de la Partida que condenaba el forzamiento de una mujer no correspondía a Bernabela porque aquella "debía entenderse estricta y precisamente" en los casos en que "la violada no consintió en alguno de los tiempos del acto" (Juzgado del Crimen, f. 536). Desde esa mirada, la capacidad de detener una agresión quedaba en poder de las mujeres y su debilidad las volvía despreciables porque lo que hacía era mostrar su consentimiento frente a una compulsión inherente a la esencia masculina. No importaba acá si había sido violada. Importaba si demostraba ser una persona que merecía ser defendida porque había tenido la capacidad y la determinación para resistir la embestida. Bernabela se había encontrado atemorizada y sus sentidos perturbados. De esa forma, la ausencia de una conciencia, lindante con una pasividad, la condenaba. A "la violada", finalmente, se le recordaba que no solo había sido violada por su culpa, por no haberse resistido lo suficiente sino que llevaría una mancha en su prestigio, una devaluación de su persona, que se actualizaría cada vez que denunciara públicamente lo que debía haber mantenido en silencio.

Resulta ilustrativa, en relación al valor jurídico dado a la resistencia, las expresiones reiteradas en una secuencia de denuncias de violación a varias mujeres, en el año 1751, en San Juan de la Frontera, provincia de Cuyo, por parte de un hombre presentado con los términos de fugitivo y ladrón. En el expediente se describen los actos extremos de violencia, a través de las presentaciones de sus madres o maridos, que precedieron a la violación insistiendo, una y otra vez, en que todas ellas se resistieron con todas sus fuerzas y medios (Archivo Histórico de la Provincia de Córdoba, Argentina (AHPC). Crimen. Autos contra Miguel Gerónimo por haber forzado a una mujer y querido forzar a otras mujeres, año 1751, legajo 7, expediente 4). 


\section{LA VOZ DE BERNABELA}

Las diversas presentaciones de Bernabela fueron leídas siguiendo la intención de comprender cómo era percibida una violación por una mujer adulta, dentro de un conjunto de condicionamientos socio-económicos y de género. En el contexto de la época, existía un sentido hegemónico de larga data sobre la violación en tanto crimen asociado a un delito de honor y, también, a un delito moral, que debía ser condenado penalmente por la justicia. Indiscutiblemente, los efectos traumáticos de un acto remiten a daños percibidos desde un conjunto de códigos culturales y sociales. Desde esta perspectiva, "para que una emoción sea sentida, percibida y expresada por un individuo, debe pertenecer de una $u$ otra forma al repertorio cultural del grupo al que pertenece" (Le Breton 71). Por su parte, los efectos traumáticos son socialmente conceptualizados en relación al lugar y a la categorización dada desde diferentes ámbitos e instituciones. En especial, en virtud de los mecanismos de reparación que la justicia prevé y aplica, dentro de relaciones, tradiciones y tensiones generadas. Asimismo, la aprehensión de la gravedad de un acto, las respuestas, reacciones y solidaridades están en íntima relación con un determinado "régimen de sensibilidad" que habilita, promueve o niega la misma (Corbin 230). En ese sentido, una sutil divergencia expresada en las categorías y terminologías utilizadas, en los mismos expedientes, daba indicios de que la violación también podía ser interpretada como una violencia propinada sobre una persona, más allá de su impacto sobre el orden socio-familiar. Al respecto, la principal querellante, referenció otros alcances y daños, sin dejar de apelar a la esfera del honor, el orden familiar y a los imaginarios sobre la castidad y la pureza femenina.

A lo largo del juicio, Bernabela Franco hizo seis presentaciones mientras que su esposo Clemente Medina, realizó solo una, un mes después del primer escrito dirigido al Virrey, en búsqueda de una reparación judicial por los daños vividos y contemplados. Estos se fueron ampliando en la medida en que la justicia fue tomando decisiones, sobre las penas dadas a Sánchez, como así también en respuesta a la violencia simbólica escalonada desplegada por el defensor en sus distintas alegaciones. Los primeros escritos estuvieron acompañados solo por su nombre, mientras que en las últimas cuatro presentaciones se sumó la firma de diferentes personas a "ruego de parte", en virtud de que las justicias de la Real Audiencia de Buenos Aires y del virrey exigían la compañía y la firma de abogados. En la presentación inicial se hizo hincapié en el pedido de una pena extrema, para Sánchez, y en la reparación material de lo extraído de su casa. Luego se aludió a otras dimensiones que diferenciaremos, analíticamente, como daños socio-jurídicos, emocionales y materiales. A través de aquellas 
es posible urdir la condición de rehén en la que Bernabela se encontró. Esto por sentirse presa de múltiples violencias, condensadas en el trauma vivido, en la sospecha jurídica, en la ambigüedad judicial, en la exposición social, en el hostigamiento moral y en la precariedad económica, signada por la condición de mujer campesina de un paraje fronterizo de la provincia de Buenos Aires.

Tras la presentación de su esposo, José Clemente Medina, realizada para reforzar la denuncia contra Sánchez por "el insulto tan execrable practicado, con mi mujer", Bernabela presentó nuevamente un escrito, luego de enterarse que el alcalde de primer voto había determinado imponerle servicio personal en la ciudad, como forma de castigo. Ante dicha información, relataba que

le ha dicho el escribano que VE por última decisión mando que el dicho agresor no pague nada y que vaya a trabajar a la Iglesia de San Juan por el tiempo de tres meses y que no se me remita recurso ninguno ante ningún juez y que me vaya a mi destino por lo que ocurro a VE como desesperada e incrédula a cerciorarme de superior mandato no creyendo que por un hecho tan execrable no hay sentencia su castigo merecido el expresado Sánchez pues mandarlo solo a trabajar en este ciudad y por tiempo tan corto es lo mismo que si estuviera ya suelto; el dejar de satisfacer el daño ocasionado en la dicha sementera perdida es dejarme perecer con mis muchas criaturas pues en esta estación nos hallamos sin tener que sembrar por este presente año y sobre todo deshonrada entre todas las gentes de que solo espero por remedio a Dios nuestro Sr. Y en su nombre que lo puede hacer VE antes de partir de esta ciudad pues según reconozco lo que pretenden es que luego que VE se ha de soltarlo se lo que seguirá grande daño en que el dicho pretenda burlarse y que mi marido haga un desatino a que dicho también ejecute por todo lo que a VE pido y suplico me mire con la caridad que acostumbra con los pobres desvalidos como yo que sea caridad que recibiré de la notoria justificación Buenos Aires, 10 de junio (Juzgado del Crimen, fs. 519 v y 521).

Desconcertada por la simbología que se desprendía de la conmutación de las penas dadas a Sánchez, Bernabela fue denotando, en un relato denso, las múltiples dimensiones que la violación había desencadenado. Desde sus efectos sociales tales como la exposición, la deshonra, la burla, las inquietudes en torno a una reincidencia o a una venganza, por parte de su marido, hasta los ecos traumáticos de los recuerdos del hecho en su vida cotidiana. Es en el registro emocional del trauma sobre el cuerpo de una persona avasallada donde 
reposaría especialmente el drama de la violación. Bajo esas circunstancias deberá movilizarse en la búsqueda de una reparación, mientras su cuerpo y su persona continuarán siendo cuestionados, vigilados y marcados por el hecho denunciado. La presentación judicial no agotaba el "círculo de la violencia", ya que con ella se daba a conocer el acto que plasmaba la "deshonra pública de la víctima" (Celis Valderrama, Delitos 8). Al respecto, Bernabela exclamó que mandara a

Este reo de mi honor se le embarguen sus bienes por ser justos resarcimientos por los perjuicios que me ha causado estando prácticamente libre para tan grave delito quedando yo con esto al mayor desamparo pues por volver y probar mi honor he gastado cuanto tenía cuando ese fue el causador de sus ruinas ya que yo quedé con esta nota de libertinaje (Juzgado del Crimen, fs. 532-533).

La persecución, instaurada a través del "arma del escándalo" y el rumor, funcionaba como dispositivo de control y reproducción de una cultura patriarcal que atravesaba todas las relaciones sociales. Lógica, que al mismo tiempo era asumida y utilizada por otras mujeres, en la representación de los valores propios de su condición de género y grupo social. En cierta forma, la violación ponía en juego la puja por la subyugación de las mujeres, en este caso a través de la apropiación forzada de su virginidad, que constituía su principal tributo, o a través de la usurpación de sus cuerpos en la consecución de un goce, vinculado a la imposición, la atemorización y al dominio perverso. La violencia no solo la instituía el propio acto sino que, en la medida que el agresor lograba su objetivo, dejaba una marca, una presencia imborrable, ligada a la consecución forzada de un deseo personal, imprimiendo el miedo y generando daño en la estima y en la valoración social de la persona afectada. Lo cual se producía, en general, sobre mujeres en condición de desprotección socio-económica y en relación de desigualdad. A través de este patrón de violencia, aquellos hombres "reforzaban su virilidad" frente a otros, desplegando la fuerza y el vigor que fuesen necesarios para alcanzar su propósito (Stern 164 y 189). Poner en juego el honor femenino implicaba doblegarla, al despojarla de su principal capital y recurso de negociación, en una sociedad significada por el mismo, produciendo una subalternidad o reproduciendo la misma.

Atacar el honor femenino condensaba una multiplicidad de efectos que se manifestaban en terrenos sociales, económicos y emocionales. Cuestionar o manchar el honor de una mujer era, en sí mismo, un acto de violencia. La esfera judicial, en tanto tribunal compuesto por "hombres notables" que dirimirían responsabilidades, configuraba el medio instituido para enmendar su honor, 
atado a la confianza que se depositaba en ella para resguardarlo así como para sostener una conducta ejemplar, incluso ante el ataque de un hombre en su casa, en medio de la noche. Probar su honestidad y su palabra, judicialmente, era una forma de reponer uno de los múltiples daños que el hecho había instaurado. El castigo públicamente dado al agresor, por otra parte, expresaba que la justicia la había escuchado y le había creído, devolviéndole nuevamente el crédito, puesto en duda. En esa búsqueda, Bernabela remarcó que

los mismos autos son verdaderos testigos de mi inocencia y ellos mismos son los que aclaran las dudas pues aun en aquel hecho acaecido hasta un pañuelo y dos pesos en plata me hizo darle y todo le fue concedido pues veía cerca mi muerte sino concedía a sus intentos (Juzgado del Crimen, f, 533).

El miedo a perder la vida o la amenaza de perderla conformaba un drama que debía ser relatado, a los fines de demostrar su inocencia en la defensa de su principal tributo. El dilema de defender el honor o la vida sintetizaba la situación de encierro en la que quedaba subsumida una víctima de violación. El horror vivido y la encrucijada emocional desatada debían ser representadas, en los Tribunales, para constatar una reacción acorde a su condición de género. De esa forma, se podía accionar en la justicia y pedir reparación. El tenso cruce entre miedo, trauma, honor, castigo y reparación fue señalado por Bernabela al insistir en que "por la violencia con que violó mi honor" la condena a destierro no debía ser conmutada en servicio personal porque no solo se "hallaría con manifiesto riesgo de que logrando profugarse atente nuevamente contra mi honor o contra mi vida", el que "a cada paso me asalta en la cama", sino que "ocurriría que todos los días se vendrían estas monstruosidades si se omiten los castigos" (Juzgado del Crimen, fs. 528, 528v, 532, 535 y 535v).

Las mujeres en los Tribunales coloniales combatieron las violencias en las que estaban inmersas con las herramientas disponibles. Esas violencias eran múltiples. Aquellas propias de una sociedad mediada por el uso de las armas blancas o de fuego para mediar conflictos bélicos como interpersonales. Así, como las que se configuraban en torno a valores y modalidades de relacionamiento de tradición occidental, como era la defensa del honor y la venganza, estructurada sobre sociabilidades violentas y modalidades infra-judiciales de resolución de desavenencias (Salinas, "Violencia interpersonal" 19). Las violencias condensadas en la negación de la otredad, en todas sus dimensiones, desde parámetros de valoración construidos sobre miradas unívocas, en torno a hombres de elites pertenecientes a la "castas de españoles". La violencia emanada 
ante la concentración de la justicia en elites hispano-criollas masculinas, con poderes locales enquistados, o por las disputas al interior de las mismas. Hasta la violencia manifestada en el propio contexto familiar, donde el castigo físico era legitimado como el medio de disciplinamiento instituido hacia hijos e hijas como hacia las mujeres, en una relación conyugal. Al respecto, en la cultura hispana y americana de fines del siglo XVIII, se concebía como legítimo al castigo físico "discreto y moderado" con el objeto de corregir y enmendar en el ejercicio de la autoridad marital, cuando la esposa incumplía normas de sujeción o cuando dañaba su honor o el de la familia. ${ }^{24}$

Dentro de ese contexto, las denuncias por maltratos y abusos conformaron una de las principales acusaciones realizadas por mujeres de sectores hispanocriollos, en los Tribunales coloniales. En Buenos Aires, estas denuncias las realizaban en gran medida mujeres de sectores subalternos, las cuales padecían actos de criminalización judicial con mayor frecuencia y menos amparo (Mallo, "La mujer" 118). En contraposición, dentro de las elites las denuncias solían ser reducidas, a los fines de evitar el escándalo social y el cuestionamiento a la honorabilidad familiar. Mantener la conflictividad y, en particular, la violencia doméstica al resguardo de la mirada externa era parte del silencio exigido para sostener el lugar de prestigio en la sociedad. Las mujeres de sectores sociales no privilegiados recurrieron con mayor asiduidad a los Tribunales dentro de una tradición jurídica que habilitó el acceso al sistema judicial a "sectores desventajados", a través de la figura de los defensores, en tanto "válvulas de escape frente a las constantes injusticias del sistema colonial" (Cicerchia 151). En el caso de las mujeres, además del espacio judicial, con sus costos materiales y sociales, se ponían en práctica modalidades interculturales de subvertir los actos abusivos del poder masculino, como los llamados "hechizos" o la preparación de alimentos que contenían efectos potencialmente negativos sobre el cuerpo de los hombres. Con lo cual se vengaba la violencia con otra forma sutil de violencia (Behar 206; Stern). Las fugas del espacio doméstico constituyeron otra forma de escapar de las violencias masculinas, que cruzaban a las mujeres de diferentes sectores sociales, jurídicos y étnicos (Quarleri, "Castigos, fugas y resistencias").

Para acceder a la mediación judicial o a algún tipo de reparación, las mujeres denunciantes solían contar con cierto respaldo político local, apoyo

24 En su estudio sobre la violencia de las relaciones conyugales en el Río de la Plata, Viviana Kluger hizo referencia no solo a la existencia de castigo disciplinares legítimos de los hombres hacia sus esposas sino también a una cultura emocional basada en fuertes sentimientos de odio, venganza y temor como guía de las acciones sociales, atravesadas por relaciones de baja afectividad (Escenas de la vida conyugal 157 y 245$)$. 
familiar y ciertos recursos materiales (Stern). Pero sobre todo debían conocer las reglas, las narrativas aceptables y los derechos de reparación a los que se podía apelar. Bernabela no refirió disponer de ayuda familiar o contar con respaldo de ninguna índole. Tampoco se hizo evidente la colaboración o protección dada por alguna autoridad, vecino o vecina. Por el contrario, quizá como parte de una postura premeditada en el juicio, Bernabela trasmitió encabezar una lucha individual, que representaba la de otras, en la que pesaba, inclusive, la culpa y la responsabilidad por las consecuencias que la violación y la búsqueda de reparación habían generado en la economía doméstica como en la persona de su marido, frente a los mandatos y códigos de honor, posesión y masculinidad de la época, al alertar sobre una posible venganza de este. ${ }^{25}$ Pese a ello, su voz, en tanto mujer envuelta en múltiples violencias, signadas por la exposición de su persona y su cuerpo, por las marcas de género, la ambigüedad jurídica, la marginalidad y las penurias de una vida campesina, con extremas durezas, en un espacio rural, precario, alejado, fronterizo, gobernador por una cofradía de hombres respaldados en sus cargos, trascendió la esfera de intimidad, la domesticidad y la inmovilidad.

Un cambio de época fue poco a poco cristalizándose a favor de que las mujeres tuvieran una alta representatividad en los reclamos realizados ante la justicia. La puesta en duda del rol de las corporaciones religiosas y el interés por la construcción de nuevos sujetos jurídicos influyó en que, a través de las burocracias borbónicas, se trazara un control directo sobre la conflictividad social y el orden familiar. Sin embargo, la experiencia de vida de las mujeres campesinas, en particular del ámbito rural rioplatense, conllevaba otros sentidos. Bajo una diversidad social, mujeres criollas, mestizas, indígenas y mulatas, jurídicamente libres, trabajaban en los campos, sostenían hogares, vendían productos y lideraban reclamos personales o familiares que denotaban, en sí mismos, un liderazgo invisible (Gresores). Bernabela fue considerada en su reclamo por la jurisdicción virreinal, que ambicionó marcar una nueva dirección en el ejercicio del gobierno y la justicia. Su reclamo, con su traslado a Buenos Aires marcó un registro inédito por el sub-registro de los casos de violación, en los archivos coloniales. Bernabela, única y a la vez representante de otras, fue expresando la necesidad de que la violencia vivida, en sus diferentes formas, no quedara en silencio. 


\section{CONCLUSIONES}

A partir del análisis de un expediente, originado tras la denuncia de una violación pergeñada a una mujer campesina, en su casa del recién fundado pago de La Matanza, se buscó ahondar, desde un enfoque micro-histórico, en las percepciones jurídicas y sociales del daño, en los mecanismos puestos en juego para obtener una reparación y en los imaginarios y dispositivos de género que actuaron para desestimar una resolución favorable o para limitar la presentación de reclamos ante la justicia. Interesó profundizar en la intervención de la justicia en sus diferentes instancias y jurisdicciones, en los posicionamientos tomados, como también en la capitalización del castigo corporal, en la forma de trabajo, para mostrar los múltiples escenarios sobre los que discurría el proceso judicial. Y, a su vez, ilustrar el rol de la justicia colonial, en tanto institución social estipulada, con fuertes contradicciones, para reordenar, reparar y reencauzar las violencias interpersonales. Se estudió un caso, en profundidad, considerando las palabras y categorías utilizadas, para atender a las perspectivas de los actores sociales. La mirada de Bernabela proporcionó especificidad a la problemática, dadas las escasas denuncias de violación realizadas directamente por mujeres. A partir de ello, se registró, especialmente, los daños vividos, mediados por las formalidades judiciales y los paradigmas sociales.

En el entramado analizado, la violación no quedó restringida a una dimensión moral, a un deshonor social, a un pecado o un atentado "contra las buenas costumbres", tal como en el universo de fines del siglo XVIII, alternativamente se la asociaba. Tampoco a la esfera corporal del trauma o al impacto emocional de la misma. Por el contrario, el acto de la violación, como las simbologías vinculadas al mismo, la persistencia del miedo, el trayecto de la denuncia y el escrutinio social y judicial, señalaron diferentes dimensiones de representación, valoración y trauma. La sospecha jurídica sobre la resistencia ejercida, el escrutinio social y los sentimientos de vergüenza, pudor y culpa, en tanto mandatos de género, alimentaron el sufrimiento. Semióticas específicas se plasmaron en los contenidos de los alegatos de las defensa y en los diferentes dispositivos desplegados, en relación a la protección del agresor o al mensaje que conllevaba el hecho, en la persona del marido, en tanto un igual pero en competencia por el control del cuerpo y la persona de una mujer.

El poder de género que estructuraba imaginarios, acciones, abusos, derechos desiguales y culpabilidades femeninas, preconcebidas, se constituyó en el eje transversal. Al respecto, la ponderación del ejercicio de una resistencia adecuada, desplegada por las mujeres contra la apropiación forzada de sus cuerpos y personas, en las instancias previas a la violación o frente al intento de 
llevar a cabo la misma, considerada durante el proceso judicial para evaluar la culpabilidad del agresor, sintetizó la ideología detrás del acto de violencia. La mirada puesta sobre las respuestas o reacciones de las mujeres dimensionaba el grado de impacto de las representaciones y relaciones de género, en estas situaciones concretas. Al mismo tiempo, desviaba la atención sobre el problema de fondo, la negación de la mujer como sujeto de derechos individuales, la sumisión de sus cuerpos al dominio de sus maridos o de sus familias e incluso de sus abusadores. Todo lo cual era respaldado jurídicamente.

Las lógicas culturales e históricas implícitas en el fenómeno de la violación se fueron entretejiendo, a través de la comparación con otros casos y a partir de la consideración de ciertas conceptualizaciones esbozadas por diferentes autores y autoras. La pretensión de sumar herramientas, a los fines de desentrañar mecanismos subyacentes en la configuración de la problemática estudiada, configuró una guía de investigación seguida por el desafío metodológico de no trasladar categorías y paradigmas del presente a la situación analizada. La intención de proporcionar algunas piezas en el armado de genealogías, estructuras de poder o matrices conceptuales, en cambio, estuvo mediada por la sensibilidad que conlleva un fenómeno de tal vigencia, violencia y trascendencia. Fenómeno que, tanto en el pasado como en el presente, muestra su complejidad conceptual y empírica, cuando se lo entiende dentro de relaciones de poder, marcaciones sociales, moralidades, ideologías de género, representaciones sexuales y narrativas culturales sobre la disposición de los cuerpos y las emociones de las mujeres. Una red entrelazada de dispositivos de dominios y abusos que han naturalizado, promovido o ignorado el dolor y el trauma o lo han enarbolado como parte de una estructura perversa y misógina.

\section{REFERENCIAS BIBLIOGRÁFICAS}

Agüero, Alejandro. "El testimonio procesal y la administración de justicia penal en la periferia de la monarquía católica, siglos XVII y XVIII". Acta HISTRIAE, no. 19, 2011, pp. 43-60. https://doi.org/10.34024/fontes.2014.v1.9186

Araya Espinoza, Alejandra. "La pureza y la carne: el cuerpo de las mujeres en el imaginario político de la sociedad colonial". Revista de Historia Social y de las Mentalidades, 8 (1/2), 2204, pp. 67-90. http://www.revistas.usach. $\mathrm{cl} / \mathrm{ojs} / \mathrm{index} . \mathrm{php} / \mathrm{historiasocial/article/view/356}$

Archivo General de la Nación, Argentina (AGNA). Tribunales, Juzgado del Crimen, "Autos contra Felipe Sánchez por haber forzado a una mujer 
casada, Buenos Aires, 25 de enero de 1778", legajo 28, expediente 16, no. 2778 , f. 497.

-----. Sala XI. Criminales, "María del Pilar, negra esclava de Jacinto Tarazona, sobre la Sevicia, que dice le causa su amo, Buenos Aires, 1785", legajo 28, expediente 16, número 2778, f. 90.

Avellaneda, Mercedes y Lía Quarleri. "Mujeres guaraníes en las misiones jesuíticas: categorías en tensión, reordenamiento social y resistencias". História Unisinos 24 (3), 2020, pp. 365-378. https://doi.org/10.4013/ hist.2020.243.03

Barral, María Elena y Raúl Fradkin. "Los pueblos y la construcción de las estructuras de poder institucional en la campaña bonaerense (17851836)". Boletín del Instituto Ravignani, no. 27, 2005, pp. 7-48. http://www.scielo.org.ar/scielo.php?script=sci_arttext\&pid=S0524$97672005000100001 \& \operatorname{lng}=\mathrm{es} \& \mathrm{nrm}=\mathrm{iso} \& \operatorname{tlng}=\mathrm{es}$

Barreneche Osvaldo. "Esos torpes deseos. Delitos y desviaciones sexuales en Buenos Aires, 1760-1810”. Estudios de Historia colonial, no. 13, 1993, pp. 29-46. http://www.memoria.fahce.unlp.edu.ar/libros/pm.201/pm.201.pdf

Barriera, Darío. Historia y justicia. Cultura, política y sociedad en el Río de la Plata (Siglos XVI-XIX). Prometeo Libros, 2019.

Behar, Ruth. "Brujería sexual, colonialismo y poderes femeninos: opiniones del Santo oficio de la Inquisición en México". Sexualidad y Matrimonio en la América hispánica. Siglos XVI-XVIII, coordinado por Asunción Lavrin, Grijalbo, 1991, pp. 197-219.

Biblioteca Nacional de Madrid (BNM). Libro de Órdenes, "Carta del Provincial Ignacio de Frías, Santos Reyes del Yapeyú, 30 de noviembre de 1699”, ms. 6979, f. 197.

Canedo, Marina. "Fortines y pueblos en Buenos Aires del siglo XVIII. ¿Una política de urbanización para la frontera?". Mundo Agrario, no. 7 (13), 2006. http://www.fuentesmemoria.fahce.unlp.edu.ar/art_revistas/pr.514/ pr.514.pdf

Castañeda, Carmen. "Violación, estupro y sexualidad en la Nueva Galicia, 1790-1821". La investigación sobre la mujer. Informes en sus primeras versiones, Editado por Vania Salles y Elsie McPhail, Colegio de México, 1988, pp. 700-715. https://doi.org/10.2307/j.ctv8bt31j.23

Celis Valderrama, Nicolás. "Delitos, violencias y escándalos sexuales en Chile: escalas de análisis metodológico (fines siglo XVIII - mediados siglo XIX)". Nuevos Mundo, Mundos Nuevos, 2018. https://doi.org/10.4000/ nuevomundo.72232 
."'Ahora veremos lo que tiene esta niñita'. El cuerpo como prueba de las violencias sexuales en el valle central de Chile, 1780-1830". Revista Historia y Justicia, no.11, 2018, pp. 191-225. https://doi.org/10.4000/rhj.4047

Cicerchia, Ricardo. "De mujeres, varones y jueces. Familia popular y justicia en la ciudad de Buenos Aires (1777-1850)". Complementariedad entre hombre y mujer. Relaciones de género desde la perspectiva amerindia, coordinado por Marie Perriu y Michel Perruchon, Abya-Yala, 1997, pp. 141-168.

Corbin, Alain, dir. "Dolores, sufrimientos y miserias del cuerpo". Historia del cuerpo. De la Revolución francesa a la Gran Guerra. Taurus Historia, 2005, pp. 203-247.

Delumeau, Jean. El miedo en Occidente (Siglos XIX-XVIII). Una ciudad Sitiada. Taurus-Pensamiento, 1978 [2012].

Fernández, Alejandra. "Las razones de la violencia y la fundamentación del castigo: una aproximación a las formas de acusación y de defensa en la justicia criminal colonial (Buenos Aires, 1776-1810)". Formas de Historia Cultural. Editoras Sandra Gayol y Marta Madero, PrometeoUNGS, 2008, pp. 275-304.

Fradkin, Raúl, comp. La ley es tela de araña. Ley, justicia y sociedad rural en Buenos Aires, 1780-1830. Prometeo Libros, 2009.

González-Gómez, Yéssica. "Las cifras del deshonor. Violencia sexual en el Obispado de Concepción, 1750-1890". Estudios trasandinos, vol. 17-1, 2012, pp. 89-102. www/doi: 10.4206/rev.austral.cienc.soc.2017.n32-0

Gutiérrez Aguilera, María Selina. "Conductas violentas, realidades cotidianas. Familia, sociedad y convivencia en el Buenos Aires del siglo XVIII". Procesos Históricos, no. 28, 2015, pp. 76-91. http://www.redalyc.org/ articulo.oa? id=20041006007

Gresores, Gabriela. "Mujeres de la colonia. Sostén invisible, principio ordenador e impulso dinámico". XIV Jornadas Interescuelas/Departamentos de Historia. Mendoza, Facultad de Filosofía y Letras, Universidad Nacional de Cuyo, 2013. https://www.aacademica.org/000-010/1042.pdf

Herzog, Tamar. "Sobre la cultura jurídica de la América colonial (siglos XVIXVIII)". Anuario de Historia del Derecho Español, no. 65, 1995, pp. 903-912. https://dialnet.unirioja.es/servlet/articulo? codigo=134634

Koulianou-Manolopoulou, Panagiota y Concepción Fernández Villanueva. "Relatos culturales y discursos jurídicos sobre la violación". Athenea Digital, 14, 2008, pp.1-20. https://doi.org/10.5565/rev/athenead/ v0n14.470

Kluger, Viviana. Escenas de la vida conyugal. Los conflictos matrimoniales en la sociedad virreinal rioplatense. QUORUM, UMSA, 2003. 
-----. "El rol femenino a través de los litigios familiares en el Virreinato del Río de la Plata (siglos XVIII y XIX)”. Iberoamericana, vol. 4, no. 14, 2004, pp. 7-27. https://doi.org/10.18441/ibam.4.2004.14.7-27

Le Breton, David. "Por una antropología de las emociones". Revista Latinoamericana de Estudios sobre Cuerpos, Emociones y Sociedad, vol. 4, no. 10, 2012, pp. 67-77. http://www.relaces.com.ar/index.php/relaces/article/view/239

Mallo, Silvia. "La mujer rioplatense a finales del siglo XVIII. Ideales y realidad". Anuario del IEHS, vol. 5, 1990, pp. 117-132.

-----. "Conflictos y armonías: las fuentes judiciales en el estudio de los comportamientos y valores familiares". Poblaciones históricas: fuentes, métodos y líneas de investigación, Coordinado por Dora Celton, Mónica Ghirardi y Adrián Carbonetti, ALAP, 2009, pp. 387-401.

Marcus, Sharon. "Cuerpos en lucha, palabras en lucha: una teoría y una política para la prevención de la violación". Debate Feminista, no. 26, 2002 [1992], pp. 59-85. https://doi.org/10.22201/cieg.2594066xe.2002.26.736

Molina, Fernanda. Cuando amar era pecado. Sexualidad, poder e identidad entre los sodomitas peruanos (Siglos XVI-XVII). Instituto Francés de Estudios Andinos/Plural Editores, 2017.

Moriconi, Miriam. "Voz y quebranto. Teodora Álvarez, esclavizada y fugitiva, en la cultura jurisdiccional en el Río de la Plata (1758)". Revista Historia y Justicia 11, 2018, pp. 1-34. https://doi.org/10.4000/rhj.4117

Néspolo, Eugenia. "Cautivos, ponchos y maíz. Trueque y compraventa, ¿doble coincidencia de necesidades entre vecinos e indios en la frontera bonaerense". Los pagos de Luján en el siglo XVIII". Revista TEFROS, Vol. 6, no. 2, 2008, pp.1-20. http://www2.hum.unrc.edu.ar/ojs/index.php/ tefros/article/view/186

Plaza, Camila. "Las flores, la pureza y el recogimiento: Imágenes e imaginarios de la feminidad en las causas criminales por estupro y rapto de la capitanía general de Chile, 1638- 1776". Revista Dos Puntas, no.16 (IX), 2017, pp. 21-41.

Quarleri, Lía. "Castigos, fugas y resistencias femeninas en el Río de la Plata colonial. Mujeres indígenas y españolas en historia conectadas". Revista de Feminismos y Género, no. 3 (2), 2019. https://doi. org/10.24215/25457284e083

-----. "Castigos físicos y control de los cuerpos. Mujeres guaraníes, trabajo y poder colonial". Temas Americanistas, no.40, pp. 239-264. http://dx.doi. org $/ 10.12795$

Riva, Betina. "Cuerpos que hablen: algunas consideraciones en torno a los delitos sexuales en Buenos Aires durante la segunda mitad del siglo 
XIX”. Revista Cambios y permanencias, no. 7, 2016, pp. 113-139. https://revistas.uis.edu.co/index.php/revistacyp/article/view/7025

Rodríguez Ortiz, Victoria. Historia de la violación. Su regulación jurídica hasta fines de la Edad Media. Comunidad de Madrid, 1997.

Salinas, René. "Violencias sexuales e interpersonales en el Chile tradicional". Revista de Historia Social y de las Mentalidades, vol. 4, no. 4, 2000, pp. 13-49. https://www.revistas.usach.cl/ojs/index.php/historiasocial/article/view/290

-----. "Violencia interpersonal en una sociedad tradicional. Formas de agresión y control social en Chile. Siglo XIX". Historia Social y de las Mentalidades, vol. 12, no. 2, 2008, pp. 9-22. https://www.revistas.usach.cl/ojs/index. $\mathrm{php} /$ historiasocial/article/view/142

Sedeillán, Gisela. "Los delitos sexuales: la ley y la práctica judicial en la Provincia de Buenos Aires durante el período de codificación del derecho penal argentino (1877-1892)". Historia Crítica, no. 37, 2009, pp. 100119. https://doi.org/10.7440/histcrit37.2009.06

Segato, Rita. Las estructuras elementales de la violencia. Ensayos sobre género entre la antropología, el psicoanálisis y los derechos humanos. Universidad Nacional de Quilmes, 2003.

Sidy, Bettina. "Sobre la reclusión, la corporalidad y las obligaciones de las mujeres en el Buenos Aires tardo-colonial. Reflexiones a partir de un caso de desavenencia matrimonial". Trashumante. Revista Americana de Historia Social, no. 15, 2020, pp. 82-102. https://doi.org/10.17533/udea. trahs.n15a04

-----. "El cuerpo de Lorenza. Reflexiones en torno a un caso de estupro en el Río de la Plata (siglo XVIII)". Boletín de Antropología Universidad de Antioquia, no. 61, 2021, en prensa.

Socolow, Susan. "Women and crime: Buenos Aires, 1757-97". Journal of Latin American Studies, vol. 12 (1), 1980, pp. 39-54. https://doi.org/10.1017/ S0022216X00017557

Stern, Steve. La historia secreta del género: mujeres, hombres y poder en México en las postrimerías del periodo colonial. Fondo de Cultura Económica, 1999.

Tomás y Valiente, Francisco. El derecho penal de la monarquía absoluta: (siglos XVI-XVII-XVII). Tecnos, 1969.

Vassallo, Jaqueline. “Es posible hacer historia del derecho desde una perspectiva de Género?”. Poblaciones históricas. Fuentes, métodos y líneas de investigación, Coordinado por Dora Celton, Mónica Ghirardi y Adrián Carbonetti, ALAP editores, 2009, pp. 427-437.

Vigarello, Georges. Historia de la violación (siglos XVI-XX). Cátedra, 1999. 